\title{
0 papel da comunicação nas aventuras da complexidade
}

\begin{abstract}
RESUMO
O papel da comunicação está sendo trilhado em uma nova leitura epistemológica da informação. A partir da teoria da complexidade em Edgar Morin, este ensaio se propõe a se aventurar pelos caminhos que a modernidade no Século XX trilhou sobre a Comunicação. Este texto viaja através da complexidade ao fazer um breve comentário sobre a Comunicação e a Informação na contemporaneidade.
\end{abstract}

\section{PALAVRAS-CHAVE}

- comunicação

- teoria da complexidade

- contemporaneidade

\begin{abstract}
The role of communication is being studied in a new epistemologic reading of information. Using Edgard Morin's complexity theory, this essay has the intention of understanding the ways modernity in the 20th century approached communication. This essay travels through complexity by making a short commentary on communication and information in contemporaneity.
\end{abstract}

\section{KEY WORDS}

- communication

- complexity theory

- contemporaneity

\section{Luis Gomes PUCRS}

U m belo dia, manhã, uma manhã cinza no dia de um homem, ele acorda. Os pensamentos são formados nas madrugadas, nos dias, no silêncio do sono. A sua formação não é uma enciclopédia, um compêndio, um quadro estático na parede sem cores nem relógios. O formato que se tem é que a vida é uma sucessão de acontecimentos, de teorias ao longo dos séculos.

Este homem atravessou parte do ocaso do século $X X$, vivendo intensamente as mudanças sofridas e impostas no Ocidente. O pensamento no mundo ocidental, uma parte viva do mundo, e que está na Complexidade de Morin, já não serve mais como uma simples descrição de fenômenos, mas o é, também. Nesse belo dia, o homem percebe que é o mesmo dessas alterações, que é parte de uma mesma coisa, de tudo no mundo. Não é literatura; é a realidade esfacelando-se a partir do momento de cada manhã em que o homem coloca seus pés novamente no chão. As idéias sobrevivem porque os homens as alimentam de novas roupas e novas informações e conforme as necessidades; os mesmos homens que as negaram tratarão de dar-lhes forma diante dos acontecimentos.

As teorias sobrevivem porque os homens se espalham pela terra e, como diz Morin (2005), o desconhecido não é apenas o mundo exterior e sim, sobretudo, nós mesmos. As crenças nas verdades, na lógica ocidental, nos fatos e no cotidiano da comunicação entre esse homem e todos pelo mundo afora e adentro, do Ocidente ao Oriente, da rua à casa, do real ao hiperreal, do conceito ao imaginário, da linguagem à comunicação e tudo na esfera do vivido, do jogo, permaneceram porque o visível passa do inteligível ao sensível e ao invisível.

Do possível ao impossível, sempre esse homem, dentro da complexa colcha do pensamento, será sua única saída para o mundo. O seu mundo diante do que está em discussão, sendo que um belo dia esse homem acordou fora do apenas inteligível; foi através da "brecha microfísica", que abrira o espaço para o sujeito se postar diante do objeto, frente ao próprio decreto mal-aventurado da lógica ocidental, que percebeu que por acaso contribuíra para suas novas manhãs.

O fato de estar no mundo, o fato de comunicar-se com o outro fez com que esse homem se valesse de todo o aparato fornecido pela era da informação, para que logo entendesse que nas sociedades teria o caminho por onde um dia se costumou dizer que o "sistema das comunicações de massa é um sistema universal". Diante das mudanças que esse homem presenciou, nada foi mais além do que o compreender metodológico por meio das interpretações no espaço 
ínfimo que existe entre ele e as teorias que o separam e o aproximam dos avanços tecnológicos atuais.

Na solidão do "fim das certezas", diria Ilya Prigogine, a contradição na tensão do mundo (1996, p. 14), “(...) do tempo e do determinismo não se limita às ciências, mas está no centro do pensamento ocidental do que chamamos de racionalidade e que situamos na época pré-socrática". Passamos, então, da certeza de um saber objetivo à necessidade do pensamento complexo. O paradoxo do uno e do múltiplo será a passagem da verdade absoluta ao tempo da incerteza, da desordem e da ambigüidade para depois se reordenar através da volta ao conhecimento, ao entendimento propriamente dito.

Morin apresenta o Paradigma da Complexidade que nos será útil como instrumento para a reflexão das metamorfoses da comunicação. É um estágio da comunicação em que a técnica não é apenas informação, mas também troca e produção de linguagens.

Com as categorias de Comunicação e Conhecimento, de Morin, passamos pela categoria de Cotidiano, em Maffesoli, e pelas categorias de Poder e Socioleto, em Barthes. Nosso propósito será estudar as novas tecnologias depois do apogeu da Comunicação de massas, empregada e legitimada pela teoria da Comunicação como sendo um dos pontos altos na desordem e na organização comunicacional propagada nas ciências humanas, e depois do fim de uma modernidade anunciada.

Durante esse acordar, o homem, que um dia se pôs prostrado em face das tentativas da ciência, viu a técnica e o pensamento se tornarem os senhores dos próximos séculos. Ele acordou, enfim, para o seu século $X X$, que terminava com o que estava oculto, o saber, a forma, o sujeito, o imaginário; esse se reerguia, como Barthes escreveu:

O que tento visar aqui é a uma responsabilidade da forma: mas essa responsabilidade não pode ser avaliada em termos ideológicos e por isso as ciências da ideologia sempre tiveram tão pouco domínio sobre ela (BARTHES, 1984, p.17).

Através da forma, da literatura, diria Barthes, e no Cotidiano, em Maffesoli, se desenha a radicalização de um tempo onde as verdades já não serão mais a única presença para legitimar o conhecimento. A tentativa da "crença na superioridade da verdade, a nãoverdade ou sobre o erro", diria Vattimo, é uma convicção de tempos remotos em que o homem poderia "conhecer as coisas em si mesmas" e que se mostra inviável:

[...] já que precisamente a análise química do processo do conhecimento revela que este nada mais é que uma série de metaforizações: da coisa à imagem mental, da imagem à palavra que exprime o estado de espírito do indivíduo e desta à palavra imposta como palavra "justa" pelas con- venções sociais; depois, novamente dessa palavra sacramentada à coisa, da qual percebemos apenas os traços mais facilmente metaforizáveis no vocabulário que herdamos (Vattimo, 1996, p. 172-173).

O que importa a esse homem não é mais saber a importância de quão grande é a realidade já sem o poder dominante da ideologia e da ciência, mas a sua participação no mundo, que se projeta não mais na sua afirmação, mas em seus postulados formais que $o$ pensamento no século XX nos legou. Como (Barthes, 1989, p. 19) "a ciência é grosseira, a vida é sutil, e é para corrigir essa distância que a literatura nos importa", diria Barthes, ao afirmar que o importante não é o que se sabe totalmente sobre algo, mas o que se sabe sobre algo que possa nos revelar como conhecedores além das coisas, conhecedores do próprio homem.

O homem é o que restou de si mesmo; ao acordar, não teve mais a ilusão de perder sua condição de ser livre e apostar nas novas descobertas que o século XX em derrocada proporcionou aos intrépidos, isto é, uma das maneiras para se continuar pensando o pensar contemporâneo. Ele não deve temer a idéia de Heidegger, que percebia a técnica como extremamente perigosa à essência humana. Nada disso é mais vital para as discussões que se sucederam após o término do medo diante da ciência que domina e da razão que se instrumentaliza, pois a linguagem sempre superará o paradigma perdido.

Para Morin (1999, p. 35-36), o "método" será mais do que uma metodologia, pois essas "são guias $a$ priori que programam as pesquisas, enquanto o método derivado do nosso percurso será uma ajuda à estratégia (a qual compreenderá utilmente, certo, segmentos programados, isto é, 'metodologias', mas comportará necessariamente descoberta e inovação)". Criando e teorizando o pensamento complexo, Morin se valerá da diferença que surge como contradição no pensamento e na realidade:

O pensamento complexo, que não pode expulsar a contradição de seus processos, não pode tampouco pretender que as contradições lógicas reflitam contradições próprias ao real. A contradição vale para o nosso entendimento, não para o mundo. A contradição surge quando o mundo resiste à lógica, mas o mundo que resiste à lógica nem por isso é “contraditório" (Morin, 2001, p. 241).

O pensamento complexo trará o reconhecimento das incertezas que servirão de base para esta tese, onde a ciência não só tem o poder de persuasão, mas o poder de danificar seus próprios fins. $\mathrm{O}$ que se esgota no racionalismo exacerbado, que se divide através da técnica, se encontra no próprio fim que não existiu e que passou pela técnica como se fosse apenas o esgotamento e a supressão do sujeito. 
No paradigma da Complexidade, toda verdade não é estanque, um fim em si, mas caminha para uma linha epistemológica próxima daquela de Feyerabend, onde não existe um método. Morin (2002, p. 456) vê o método da complexidade se impondo primeiramente na sua "impossibilidade de simplificar", surge lá onde o cientista descobre (Feyerabend, 1997, p. 292) "fatos e leis e faz aumentar constantemente o volume do conhecimento seguro e indubitável".

Para Morin, é nas incertezas que a complexidade com seu sujeito-observador terá, nas antinomias, o divagar do curso das racionalizações:

A complexidade não é complicação. O que é complicado pode se reduzir a um princípio simples como um emaranhado ou um nó cego. Certamente o mundo é muito complicado, mas se ele fosse apenas complicado, ou seja, emaranhado, multidependente etc, bastaria operar as reduções bem conhecidas: jogo entre alguns fenômenos na linguagem. (...) O verdadeiro problema, portanto, não é devolver a complicação dos desenvolvimentos a regras de base simples. A complexidade está na base (Morin, 2002, p. 456).

Vivemos na ressaca do apogeu da globalização ${ }^{1}$, em que a informação é mais do que a comunicação que hoje poderá nos oferecer, mas ao mesmo tempo existe essa (Giddens, 1991, p. 69) "intensificação das relações sociais em escala mundial", na qual o tempoespaço nas relações sociais é fundamentado em um distanciamento que se aproxima muito mais através do local para uma conexão simultaneamente com o resto do mundo. As novas tecnologias são a prova mais concreta de que a comunicação cumpre o seu papel que foi o de sempre informar e de ser o ato de compreender uma tarefa dos que também emitem e recebem o significado de uma informação.

A compreensão, para Gadamer (2002, p. 216), será a tarefa de toda a "compreensão é linguagem" e quando Morin (2001, p. 42) diz que não se deve confundir "comunicação e compreensão, porque a comunicação é comunicação de informação às pessoas ou aos grupos que podem entender o que são significação e informação", se observa que este autor não vai ao encontro do diálogo interno existente na linguagem com o sujeito. As possibilidades das linguagens existentes que pulsam do pensamento e da ciência encontram na literatura sua forma mais perfeita de retomar o sujeito para dentro de uma nova comunicação.

Aqui se entra no que Barthes (1989) chamou de maquinaria da linguagem, que será o embate da linguagem com seus propósitos e que enfrenta, como em um jogo, toda e qualquer determinação para que ela seja perfeita, lógica e que cumpra seu destino. A linguagem não tem um destino, pelo menos a que estamos buscando analisar, a linguagem que permeia desde a comunicação de massas, passando pelo domínio da informação e, hoje, das novas tecnologias.
Barthes desconstrói a idéia de que existiria um método para legitimar as ciências, nos levando pelos caminhos da semiologia. Contudo, não é esse propriamente dito o que habita o fato de existir na linguagem, na comunicação, a compreensão das coisas. Se vai mais além ou aquém quando ele tensiona o método:

Não se pode ter por objeto senão a própria linguagem, à medida que ele luta para baldar todo $o$ discurso que pega: e por isso justo dizer que esse método é também ele uma Ficção: proposta já avançada por Mallarmé, quando pensava em preparar uma tese de lingüística: "Todo o método é uma ficção. A linguagem apareceu-lhe como instrumento da ficção: ele seguirá o método da linguagem: a linguagem se refletindo" (Barthes, 1989, p. 42-43).

O começo do desaprender a que Barthes se refere está na hermenêutica que Gadamer busca na compreensão por meio do diálogo na linguagem e as "técnicas modernas da informação", com as quais que se quebra o elo entre o sujeito e o diálogo, podem

(...) estar apenas nos inícios de sua perfeição, e que, a crer-se nos profetas da técnica, logo tornarão obsoletos tanto o livro e o jornal quanto mais os ensinamentos que procedem dos encontros humanos, fazem-nos lembrar aqueles que são o oposto mais radical. Refiro-me aos carismáticos do diálogo que mudaram o mundo: Confúcio, Buda, Jesus e Sócrates (Gadamer, 2002, p. 244 § 208).

Em outro sentido, pensamos que no prazer que existe no "texto" em Barthes, onde o corpo segue as próprias idéias e, sendo assim, se diferencia do "eu", a duplicidade se revela e o método é parte da linguagem no texto e na sua subversão diante do real. O que se vê entre os autores é a tentativa de reconstituir a comunicação, por meio da linguagem e da compreensão daquilo que se tem como informação.

Para Gadamer, o fato da incapacidade para o diálogo é um dos fenômenos comunicativos; em Morin, a comunicação só se realiza através da compreensão entre as pessoas. E por último, em Barthes, a textura anárquica da literatura como linguagem é o que salva o pensamento das ciências, que tentava aperfeiçoar como ele escreveu o que ele escreveu que a literatura estaria trabalhando nos interstícios da ciência, pois está antes ou depois em relação a ela.

A Comunicação no século XX alcança sua similitude com o que dela se perdeu, isso para os que buscam a perfeição da ação comunicativa e para os que vêem as diferenças da entropia comunicacional como continuidade da linguagem possível entre as ciências, e aqui o que mais nos interessa, a comunicação e as novas tecnologias.

Michel Maffesoli busca na tradição anárquica e 
libidinosa do pensamento ocidental, com muita acuidade e inteligência, o que há de melhor e o que há de pior no pensamento ocidental para refletir o homem do século $X X$ e seus limites até o homem do século XXI. O que distanciou os projetos, ao longo do século passado, da modernidade em sua eterna agonia com o homem não foi a falta de projetos, mas o seu imanente projeto obsedado entre a razão garantida e a promessa de um mundo melhor. Maffesoli segue sua trajetória intelectual pelo caminho mais caro do pensamento no século XX, por meio da filosofia heideggereana e da fenomenologia para compreender com precisão quais são as brechas e falhas nesse projeto remanescente, ainda dos ideais Iluministas, para tocar exatamente no ponto crucial, na falha desse projeto.

A supervalorização do ideal humano, a afirmação do sujeito eivado pela razão e por uma ética nos moldes de Kant: é aqui que o sociólogo e pensador da pós-modernidade dá seu tiro certeiro. Sua crítica engajada e anárquica vê na sociologia compreensiva, na tradição de Georg Simmel, um instrumental filosófico para discutir com a modernidade que sua tese sobre a pós-modernidade é mais uma constatação de um novo tempo do que um desejo, tal qual seus críticos insistem, no desespero por estarem órfãos, em lhe atribuir.

Maffesoli retoma o espírito do homem-individual, do homem-lúdico. É com esse homem que o presenteísmo toma conta daquilo que fora jogado na lata do lixo do Ocidente. O imaginário social refletido pelo pensador, e como gosta para si próprio, "velho anarquista", está como ponte entre as diversas formas de comunicação no século XXI.

Umberto Eco (1987, p. 345), em A estrutura ausente, dirá mais sobre o sujeito em uma concepção mais psicanalítica na qual o homem é capturado em uma espécie de armadilha, na qual não há forma presente e a realidade, ao invés de se impor, entra em um "jogo de vaivens, subterfúgios, derrisões...", que descreve o fato de que não existe fórmula certa de restituir o "sujeito", pois na relação entre o analista e o analisado a verdade não se expõe como uma verdade posta e sim como um jogo de esconder e "eludir". Da mesma forma, ela se coloca novamente em cena sem um fundamento transcendental entre o $(1987$, p.346) "sujeito e o ser que fala".

O século XX perfaz sua trajetória entre a modernidade e seu esgotamento, passando pela pós-modernidade durante períodos nos quais a modernidade fazia jus ao seu nome, fosse pela ciência, fosse no pensamento ou na literatura. Dirá Vattimo que a modernidade é a época da superação e que ao se superar sempre está envelhecendo e buscando o novo e que para Nietzsche esse recurso de sempre ultrapassar seria uma categoria tipicamente moderna. Vattimo complementa:

Não penas a modernidade é constituída pela categoria da superação temporal (a inevitável sucessão dos fenômenos históricos de que o homem moderno se torna consciente por causa do excesso de historiografia), mas também, segundo a conseqüencialidade muito estrita, pela categoria da superação crítica (Vattimo, 1996, p. 173).

Para Vattimo (1992), vivemos no tempo da sociedade da comunicação generalizada, em que as ciências humanas antes eram atreladas ao discurso de apreensão do saber, como o da cultura, da antropologia, da psicologia, e que constituíam a sociedade moderna como a sociedade da comunicação. O que se deve observar é que passamos do âmbito do socialismo lógico, do homem emancipado pelo ideal dos cientistas, e do (1992, p. 31) "ideal da comunidade ilimitada da comunicação". Em vez de "avançar em sua autotransparência, a sociedade das ciências humanas e da comunicação generalizada" rumou para um tipo de "fabulação do mundo".

O que proporemos, aqui, é realizar o diálogo entre os textos que marcam o debate entre a modernidade, a sociedade da comunicação e as novas tecnologias, transpassado pela discussão da pós-modernidade que não está em conformidade com o mito de um ideal de comunicação. Além disso, os autores elencados darão o corpus teórico para esta tese.

Assim foram escolhidos os Blogs, signos de um tempo, onde a comunicação tem sua relevância nas novas tecnologias como análise para este trabalho. Não esgotaremos as possibilidades como crítica e nem a análise de que neste século a Era da Internet tem seu destaque nas comunicações. O que se buscará é tecer o quadro teórico que envolve a discussão entre a comunicação e a informação, passando pela apropriação e pelo sentido desta tecnologia como mais uma forma de saber e não apenas de receber uma informação.

O século XX teve seu apogeu por ser a era da informação, da cultura de massa; o rádio e a televisão abriram os espaços para a disseminação dessa informação. A simultaneidade demarcou os matizes do poder, das ideologias sendo atravessadas pela publicidade e pelo marketing. As razões da indústria cultural sobre a vida formataram um novo quadro na comunicação. Deixou-se de lado o simples fato de informar para formar e se passou para o lado do intervir e ao mesmo tempo este século foi o século no qual a diversidade permitiu maior acesso à informação.

Alguns teóricos chamam o século passado de a "era do rádio" e da "televisão". Para Mattelart, o ponto em que os sistemas tecnológicos complexos de comunicação e informação mudaram o cenário e a relação entre a sociedade e o indivíduo. Uma nova ordem mundial surgiu. A idéia de rede toma corpo através da cibernética e a comunicação se interliga com os sistemas comunicacionais através da aceleração tecnológica da informação.

Para Lyotard, o domínio do saber deixa de existir, 
isso que aqui nos interessa primeiramente, mas as grandes narrativas, ao perderem sua legitimidade, cedem ao se desagregarem diante dos ideais do idealismo alemão e do apogeu do sentido emancipatório nos anseios da Revolução Francesa. Desmorona-se o ideal de progresso dos macrossujeitos que buscavam a redenção de suas causas. O fragmento é parte integrante do todo. Em texto escrito como relatório ao Conselho das Universidades do Québec, Lyotard, em O pós-moderno, coloca o saber científico como mais um discurso:

O saber científico é uma espécie de discurso. Ora, pode-se dizer que há quarenta anos as ciências e as técnicas ditas de vanguarda versam sobre a linguagem: a fonologia e as teorias lingüísticas, os problemas da comunicação e a cibernética, as matemáticas modernas e a informática, os computadores e suas linguagens-máquinas, os problemas de memorização e os bancos de dados (...), eis aí algumas provas evidentes, e a lista não é exaustiva (Lyotard, 1988, p. 5).

O excesso dessas informações tecnológicas é considerável sobre o saber e a partir desse conhecimento a comunicação se torna cada vez mais um ponto de extrema importância no final do século passado. A legitimação, para Lyotard, se dá através do dissenso na composição de jogos de linguagens, como Wittgenstein o fez no estudo da linguagem ${ }^{2}$, do ponto zero se parte com enunciados, daí se constroem os jogos, a interação na dissolução das regras antes preestabelecidas.

Assim, dirá Lyotard sobre os jogos de linguagens, que (Lyotard, 1988, p. 17) "suas regras não possuem sua legitimação nelas mesmas", mas nelas existe um tipo de contrato categórico ou não entre os jogadores. Ao mesmo tempo existem as regras que validam um jogo, como no xadrez; o mínimo movimento ao contrário em um lance modificará a natureza do jogo.

O século XXI, para muitos, será a Era da Internet, onde existia a emissão a milhões de ouvintes e telespectadores, neste século será a vez de milhões de pessoas conectadas na rede mundial de computadores publicando suas falas, seus registros e gerando conteúdo. Os avanços na computação e nas pesquisas acadêmicas nos anos 90 aconteceram,

[...] entre setembro de 1993 e março de 1994, quando uma rede até então dedicada à pesquisa se tornou a rede de redes, aberta a todos. No mesmo período, o acesso público a um programa de navegação (Mosaico), descrito na seção de negócios do New York Times de dezembro de 1993 como "a primeira janela para o ciberespaço", tornou possível atrair usuários - na época chamados "adaptadores" - e provedores, os pioneiros em programas (Briggs, 2004, p. 310).
Com essa corrida tecnológica, a tecnologia da comunicação se mostrou mais viva do que nunca com o advento da Internet e com as relações entre informação do emissor ao simples receptor. Isso custou caro demais para a Teoria da Comunicação, que buscou as explicações mais diversas sobre o que chamaríamos da crise da comunicação de massa, através da indústria cultural que se renovou, por meio da informação que passou a ser vista para além de uma mercadoria, mas estando diante do seu próprio fim, ou seja, de sua disseminação enquanto informação e consumo e o espalhar da informação pelo intermédio do mundo no ciberespaço.

Virilio (1996, p.63) dirá que a "velocidade é a esperança do Ocidente" e que ela dá sustentação às forças que protegem o Estado, mas ao mesmo tempo pelo signo de uma dromologia (velocidade), se vê a impossibilidade de teoria da informação e o que era inerte se torna o símbolo do (Matterlart, 2000, p. 180) "progresso e de domínio do meio". A velocidade entra nas vidas como se entrasse nos sistemas em uma instantaneidade e a noção de duração acaba sendo absorvida por essa hipercepção; assim, o tempo comum já não será mais possível. Tudo está interligado, em rede.

Baudrillard vai mais longe sobre a idéia de Comunicação, sobre a emancipação do homem diante do progresso da informação. Hoje o homem é vítima do próprio excesso de comunicação. Ele chama de "paradoxo operacional":

[...]não apenas não se trata de fazer-valer, mas o melhor ainda é nada valer pra melhor fazer valer - nada saber para melhor fazer-saber nada produzir para melhor fazer-produzir - nada ter que dizer para melhor comunicar.

Para a comunicação e a informação, a conseqüência é inexorável: para que algo transite melhor e mais depressa, é preciso que o conteúdo esteja no limite da transparência e da insignificância (Baudrillard, 1990, p. 56).

Temos como resultado as "fantasias da comunicação", como diria Baudrillard, e que essa "boa comunicação" passa pelo seu fim, o aniquilamento do seu conteúdo. Baudrillard dirá que a (1990, p. 57) “boa informação passa pela transparência digital do saber" e que o fato de comunicar só nos garante que o social deixou de existir e a forma de socialidade passa pela perda do controle de quem a usa. Ele complementa que a (1990, p. 63) "tela é virtual, logo, instransponível. Por isso presta a essa forma abstrata, definitivamente abstrata, que é a comunicação".

Este trabalho tem como objetivo fazer a reflexão em relação aos aspectos referentes ao Ciberespaço, suas tramas diante da idéia do virtual, do uso dessas tecnologias sem perder de vista o lugar do pensamento, onde o homem ainda consegue, nesse espaço, reavaliar o que é para o bem e os estragos trazidos, para os mais pessimistas, pelas novas tecnologias. A escolha 
foi analisar o uso da rede, da Internet; trata-se de uma análise de Blogs, em dois deles, entre os milhares que existem no Brasil. Um deles foi escolhido porque representa o registro do cotidiano de um taxista, Mauro Castro. O outro Blog representa a mídia tradicional, o Blog do Marcelo Coelho, jornalista da Folha de São Paulo.

O diário virtual, como são chamados os Blogs, entra no mundo da blogosfera, o espaço onde todos os bloggers (autores) exercitam seu pensamento público, ou seja, colocam suas idéias na grande massa do mundo da rede, ligados no ciberespaço, onde o emissor e receptor estão em todos os lugares ao mesmo tempo. Cada um poderá colocar seu post (cada texto inserido no blog), tornando público o que uma pessoa gostaria de falar aos outros.

Para Jonh Batelle, jornalista e professor americano, em entrevista à revista Época, os Blogs representam o (Revista Época, 2006, p. 104) "trabalho público de uma pessoa" e o que os tornam ao mesmo tempo fascinantes pela mídia tradicional também é uma ameaça ao domínio exclusivo da informação, por isso ela agregou os Blogs ao seu espaço da comunicação.

Batelle é um otimista desta nova forma de comunicar, em que qualquer internauta poderá passar sua idéia sobre um acontecimento, opinar, discorrer sobre os acontecimentos, ou melhor, tornar suas idéias visíveis na rede. Os Blogs, para muitos, são a panacéia que resolveria os problemas do domínio da informação, mas o que se tem de concreto é que temos mais uma ferramenta de informação para nos comunicarmos.

Essa aproximação da literatura ao cotidiano das pequenas coisas, o que dá sentido histórico ao conceito de crônica, torna ao mesmo tempo o trabalho de Mauro Castro próximo da mídia mais clássica por excelência do que o jornal, com o imaginário de um novo espaço, o da rede, onde o ciberespaço é, também, o cotidiano onde os internautas se manifestam. Daí o resultado do sucesso de Taxitramas foi mais que surpreendente; seu autor revelou-se um escritor, um sujeito que tem o domínio da escrita, um observador do cotidiano, onde tudo que passa aos seus olhos é registrado por ele. Mauro Castro ganhou fama imediatamente na rede, com milhares de acessos nesses dois anos de blog. Se tornou um blogueiro (blogger), na linguagem usada por ele.

Outro aspecto de nossa escolha foi o fato de selecionarmos um blog ligado a um grande grupo jornalístico no Brasil, a Folha de São Paulo, o que ajudará na nossa tese no sentido de melhor trabalharmos essa problemática das mídias clássicas (no sentido de ser o jornal), por meio da apropriação, da sua página em versão on-line, desse novo recurso, o uso de Blogs. Entre os que estão na Folha On-line, os blogs políticos, os de futebol, escolhemos o de Marcelo Coelho porque justamente nos oferece o tipo de apresentação e formato dos textos que poderemos discutir sobre as linguagens encráticas e acráticas, com possibilidades de cruzar nossas análises sobre a importância desses discursos na legitimação do Poder que se relaciona com as mídias mediadas e as mídias não-mediadas (blogs).

Isso se dá porque nas mídias tradicionais existe o controle sobre os conteúdos gerados. Contudo, nos blogs esse controle será exercido por cada autor. Poderemos sugerir que esses blogs, que são hospedados nesses grupos, têm um dono maior, que é o dono do grupo. Já nos blogs que estão na rede, criados por internautas, como é o caso do Taxitramas, há maior liberdade de interagir com os leitores.

Essas questões serão nosso desafio para analisarmos esses tipos de mídias, as não-mediadas, mais diretas com as informações adquiridas em blogs que fazem parte de grupos de mídias. Foram essas questões postas para nossa tese que nos levaram a buscar nos blogs uma mescla de conteúdos vindos de um jornalista e, por outro lado, de um blogueiro que é taxista e trabalha com o cotidiano de uma outra forma. Trata-se de uma narração do cotidiano.

Mauro Castro, 43 anos, viamonense, casado, pai da Bruna Castro (blogueira), de 11 anos, que dá as dicas e conhece as ferramentas com mais habilidade que o pai. Ele é taxista em Porto Alegre há 20 anos, com segundo grau completo. Antes da fase "Taxitramas", sua única experiência "literária" foi um pequeno fanzine chamado SCÓRIA, editado, ilustrado e distribuído por ele mesmo e por um amigo da vila Intercap, onde mora até hoje em Porto Alegre.

A escolha do Mauro Castro se deu porque se trata de um escritor e blogueiro que tem sua profissão como taxista e passa para o seu diário virtual e para as páginas de um jornal suas impressões do cotidiano. Buscamos trazer ao nosso estudo esses aspectos, que certamente nos levarão aos fenômenos das novas tecnologias, da Internet; acreditamos nisso também porque estarmos diante da trajetória de um taxista e colunista do jornal Diário Gaúcho, onde escreve suas crônicas há três anos, mesmo tempo de vida do seu blog Taxitramas.

A fama de Mauro Castro ultrapassou fronteiras, pelo menos no que diz respeito ao seu blog, pois é acessado por países não só de língua portuguesa. Essas fronteiras, da linguagem, não são empecilho para a rede se disseminar como informação, como troca de idéias ou simplesmente como trocas entre leitores que entram no seu blog e se comunicam, gerando e dando continuidade aos conteúdos propostos pelo autor. Como motorista de táxi, Mauro se autodenomina um "taxista blogueiro". Ganhou notoriedade pelo uso que faz da linguagem, da escrita, em narrar o imaginário do que está dentro do seu carro e do que se passa através das histórias contadas pelos passageiros.

O Taxitramas ganhou o mundo do Ciberespaço, atravessou as fronteiras desse espaço e foi registrado pela mídia, em jornais e redes de tvs. Com seus textos no jornal e no blog, criou sua marca na saudação ao final 
dos textos, "há abraços", forma de se despedir e de saudar a continuidade entre os leitores e o que liga ele aos sentimentos que transmite em suas crônicas. Mauro Castro é leitor contumaz de romances, crônicas, de romancistas como o português Lobo Antunes, nada mais sofisticado em sua escolha, como leitor das crônicas do jornalista David Coimbra da Zero Hora, sobre futebol, que entram no imaginário do cidadão comum, do cotidiano e das histórias sobre o imaginário mais popular. Eclético, Mauro é um cartógrafo do volante e do blog.

Marcelo Coelho, 47, escreve semanalmente no jornal Folha de São Paulo (Ilustrada) desde 1990. Faz parte do Conselho Editorial da Folha. Paulista da capital, é formado em Ciências Sociais e é mestre em Sociologia pela USP, com a dissertação Brasília e a ideologia do desenvolvimento. Autor de dois livros de ficção, Noturno, pela ed. Iluminuras, e Jantando com Melvin, da ed. Imago. Como ensaísta, participou de diversas coletâneas, como Civilização e barbárie, A crise da razão, Poetas que pensaram o mundo (organizadas por Adauto Novaes, Companhia das Letras). Também é autor de Montaigne e Crítica cultural: teoria e prática (ed. Publifolha), além de dois livros infantis, A Professora de desenho e Outras histórias, e Minhas férias, pela Companhia das Letras (Companhia das letrinhas).

A escolha dos dois blogs se deu devido à aproximação temática entre o perfil dos autores e porque os dois escrevem em jornal. O blogger Mauro Castro é um motorista de táxi e colunista de um jornal popular de Porto Alegre que criou o seu blog. No caso do blog do Marcelo Coelho, como é chamado, se trata de um jornalista que tem seu trabalho no próprio jornal, na Folha de São Paulo. O nosso propósito é analisar as semelhanças e dessemelhanças entre os registros. No que tange à nossa análise, esta tese irá requerer um detalhado estudo das fontes, das linguagens de cada blog e tudo que estiver ao alcance dos leitores na Internet. A partir desses dois blogs elaboraremos o caminho teórico labiríntico de nossa escolha.

Serão realizadas análises dos textos nos blogs, tomando de cada autor cinco textos de cada com dois comentários dos internautas, assim como será feito o detalhamento das intervenções, que servirão de base para a reflexão desse fenômeno na rede. Do taxista das palavras, buscamos as seguintes crônicas: "A diarista", "A violência banalizada", "Crônica de um engano", "Crônica de uma noite fria" e "Drogas, mágoas e uma pistola automática". Através da leitura de seus mais de 170 "causos", relatos em forma de crônicas, sejam contadas pelo autor, vivenciados por ele mesmo, se percebe o quanto o mundo real está próximo do virtual. Tudo se forma no relato, ganha forma no conteúdo entre o acontecer e o que se passa nos passageiros que isso acaba atraindo não só o leitor do jornal, mas quando ganha o mundo virtual, ganha uma nova linguagem.

As diferenças, a matriz dos textos que origina o fazer de cada texto é o que nos leva a crer, a estudar, também o perfil de quem acessa os blogs. Nesse primeiro momento será analisado um texto do Marcelo Coelho para ilustrar nosso estudo e ajudar na reflexão e aplicação das categorias propostas no trabalho.

Do blog do Marcelo Coelho escolhemos cinco textos, que serão analisados através da aplicação das categorias e dos cruzamentos teóricos registrados a partir dos temas abordados pelo jornalista. Escolhemos dois textos que têm uma continuidade, a saber: "O esquecimento da política", "Os argumentos de Paulo Betti", "Esqueçam Paulo Betti", "Buenos Aires $100 \mathrm{~km}$ " e "O momento literário (3)". No último texto, Marcelo Coelho faz o próprio comentário de uma resenha sua ao jornal sobre o escritor João do Rio.

Entrar no imaginário dos blogs, na produção de sentidos, na cultura, onde a blogosfera corresponde à passagem para uma concepção de comunicação generalizada empregada por Vattimo às sociedades pós-informacionais é o que pretendemos em nossa pesquisa, que vai desde os estudos sobre a modernidade e o fim da modernidade (não queremos expressar aqui a pós-modernidade como pensamento), mas como uma tomada de novos valores de uma nova estética a partir da arquitetura.

Outro ponto importante que será desenvolvido são as linguagens que servem para análise dos blogs. Não partiremos simplesmente para descrição de textos, mas para a análise dos materiais escolhidos, que se mesclam ao cruzar os registros entre os blogs, entre os fenômenos que existem na Internet e no fazer da notícia, pois estamos diante de uma forma diferente de mídia, não-mediada e agora mais direta. Da mesma forma, procuraremos voltar nossa reflexão sobre as questões que percorrem desde os valores modernos do pensamento contemporâneo aos paradigmas das ciências e das tecnologias na Comunicação. mamecos

\section{NOTAS}

1. Usamos aqui o termo "globalização" na acepção teórica empregada por Giddens, que se refere ao "ao processo de alongamento, na medida em que as modalidades de conexão entre diferentes regiões ou contextos sociais se enredam através da superfície da Terra como um todo".

2. Aqui nos valemos de Wittgenstein, quando ele coloca que o uso da linguagem nas palavras é "considere, por exemplo, os processos que chamamos de jogos. Refiro-me a jogos de tabuleiro, de cartas, de bola, torneios esportivos. (...) Pois, se você os contempla, não verá na verdade algo que fosse comum a todos, mas verá semelhanças, parentescos, e até toda uma série deles. Como disse: não pense, mas veja!" Wittgenstein. Investigações filosóficas. São Paulo: Nova Cultura, 1989 , p. 38. 


\section{REFERÊNCIAS}

BARTHES, Roland. Aula. São Paulo: Cultrix, 1989.

—_. O Rumor da Língua. Lisboa:Signos Ed., 1984.

BAUDRILLARD, Jean. A Transparência do Mal. Ensaio sobre os fenômenos extremos. Campina: Papirus, 1990.

BRIGGS, Asa, BURKE, Peter.Uma história da mídia: de Gutemberg à Internet. Rio de Janeiro: Jorge Zahar, 2004.

ECO, Umberto. A Estrutura Ausente. São Paulo: Perspectiva, 1987.

FEYERABEND, Paul.Contra o Método. Rio de Janeiro: Francisco Alves, 1977.

GADAMER, Hans-Georg. Verdade e Método II: Complementos e índice. Petrópolis: Vozes, 2002.

GIDDENS, Anthony. As Conseqüências da Modernidade. São Paulo: Editora da Unesp, 1991.

HEIDEGGER, Martin. A Origem da Obra de Arte. Lisboa: Edições 70, 1990.

—. Ser e Tempo.Parte 1. Petrópolis, RJ: Vozes, 1988.

—. Ser e Tempo.Parte 2. Petrópolis, RJ: Vozes, 1988.

LYOTARD, François. O Pós-Moderno. Rio de Janeiro: José Olympio, 1988.

MAFFESOLI, Michel. A Conquista do Presente. Rio de Janeiro: Rocco, 1984.

—. A Contemplação do Mundo. Porto Alegre: Artes e Ofícios, 1986.

—. A Transfiguração do Político - A Tribalização do Mundo. Porto Alegre: Sulina, 1997.

_- A Violência Totalitária- ensaio de antropologia política. Porto Alegre: Sulina, 2001.

—_. Elogio da Razão Sensível. Petrópolis, RJ: Vozes, 1998.

_. O Conhecimento do Quotidiano. Lisboa: Vega, 1987.

——. No Fundo das Aparências. Petrópolis, RJ: Vozes, 1996.
MATTELART, Armand. Comunicação Mundo. Histórias das Idéias e das Estratégias. Petrópolis, RJ: Vozes, 1994.

História da Sociedade da Informação. São Paulo: Edições Loyola, 2002.

- História das Teorias da Comunicação. São Paulo: Edições Loyola, 1999.

MORIN, Edgar. As Duas Globalizações. Complexidade e Comunicação. Uma Pedagogia do Presente. Porto Alegre, Sulina-Edipucrs, 2001.

- O Método 1. A Natureza da Natureza. Porto Alegre: Sulina, 2002.

- O Método 2. A Vida da Vida. Porto Alegre: Sulina, 2001.

. O Método 3. O Conhecimento do Conhecimento. Porto Alegre: Sulina, 1999.

. O Método 4. As Idéias. Porto Alegre: Sulina, 2001.

. O Método 6. A Ética. Porto Alegre: 2005.

NIETZSCHE, Friedrich. A Gaia Ciência. São Paulo: Companhia das Letras, 2001.

—. A Genealogia da Moral. Lisboa: Guimarães \& C. Editores, 1976.

- Humano, Demasiado Humano: um livro para os espíritos livres. São Paulo: Companhia das Letras, 2000.

PRIGOGINE, ILaya. O Fim das Certezas. São Paulo: Editora da Unesp, 1996.

SIMMEL, Georg. A Metrópole e a Vida Mental. In: VELHO, Otávio Guilherme (Org.). O Fenômeno Urbano. Rio de Janeiro: Guanabar, 1987.

—. Sociologia. São Paulo: Ática, 1983.

VATTIMO, Gianni. A Sociedade Transparente. Lisboa: Relógio D’Água, 1992.

—. . Fim da Modernidade. São Paulo: Martins Fontes, 1996.

VIRILIO, Paul. Velocidade e Política. São Paulo: Estação Liberdade, 1996.

WITTEGENSTEIN, Ludwig. Investigações Filosóficas. Os Pensadores. São Paulo: Nova Cultural, 1989. 